\title{
FOGONES DE LOS CAZADORES-RECOLECTORES \\ DEL HOLOCENO TARDÍO EN EL NORTE \\ DE TIERRA DEL FUEGO: CONTEXTOS Y ANTRACOLOGÍA
}

MAURICIO MASSONEa \& MARÍA EUGENIA SOLARI ${ }^{b}$

\section{RESUMEN"}

Se evalúa la información contextual de cinco sitios arqueológicos y sus fogones, ubicados en las localidades de Marazzi y Tres Arroyos en el amplio valle de origen glacial que une las bahías Inútil y San Sebastián, en el norte de Tierra del Fuego. Se informa del análisis antracológico realizado a partir de los carbones de estos fogones atribuidos a filiación selk'nam y a sus posibles antecesores, con un rango cronológico aproximado de 1.218 a 93 años cal. AP y se intenta una interpretación de los antecedentes reunidos. del Fuego.

PALABRAS CLAVE: cazadores-recolectores, fogón, contexto arqueológico, antracología, Tierra

\section{HUNTER-GATHERER HEARTHS FROM THE NORTH OF TIERRA DEL FUEGO DURING THE LATE HOLOCENE: CONTEXTS AND ANTHRACOLOGY.}

\section{ABSTRACT}

Contextual information from five archaeological sites and its hearths are evaluated. They are located in Marazzi and Tres Arroyos localities, within the valley of glacial origin that connects Inutil and San Sebastian bay, from the north of Tierra del Fuego. Anthracological analysis done on the basis of charcoal from these hearths linked to selk'nam affiliation and their predecessors are evaluated. The chronological range is between approximately 1.218 and 93 years cal. BP. An

a Investigador asociado, Centro de Estudios del Hombre Austral, Instituto de la Patagonia, Universidad de Magallanes. mauricio. massone@gmail.com

b Laboratorio de Arqueobotánica e Historia Ambiental. Instituto de Estudios Antropológicos. Universidad Austral de Chile. Valdivia.

Parte importante de los estudios incluidos en esta publicación se basaron en información reunida a través de los proyectos FONDECYT 90-0001, 1960027, 1020004, 1060020 y 1140939. Los antecedentes arqueológicos contextuales que se presentan, forman parte de un estudio más amplio en relación al fuego y los fogones de los grupos cazadores-recolectores del Holoceno tardío en el norte de Tierra del Fuego, que desarrolló el primer autor en el marco de su tesis de doctorado, en la Universidad Central de la Provincia de Buenos Aires, Olavarría. 
interpretation of these records is presented.

KEY WORDS: Hunter-gatherers, hearth, archaeological context, anthracology, Tierra del Fuego.

\section{INTRODUCCIÓN}

Entre los años 1990 y 2005 se desarrollaron los proyectos de investigación Fondecyt 90-0001, 1960027 y 1020004 dirigidos por el primero de los autores, que permitieron, entre otros propósitos, reunir información sobre un total de 24 fogones situados entre la costa norte de Tierra del Fuego y la sierra Carmen Sylva, por el sur, atribuidos a los selk'nam del norte o a sus antecesores, con un rango cronológico algo superior a los últimos dos milenios. Para el estudio de estos fogones se utilizaron los antecedentes ambientales y etnográficos conocidos, así como la información arqueológica, antracológica, tafonómica y actualística. El enfoque arqueológico incluyó cuatro niveles de análisis. El primer nivel se refirió al tamaño, potencia y forma de los fogones; el segundo al análisis del contenido interior de los fogones; el tercero abarcó el estudio de los fogones y sus asociaciones contextuales y el cuarto nivel trató la distribución espacial de las señales de fuego en el paisaje. Finalmente se integraron y discutieron los antecedentes reunidos mediante las distintas líneas disciplinarias (Massone, 2017).

Entre otros antecedentes de interés cabe destacar que 14 de los 24 fogones estudiados presentan un tamaño mediano, entre 31 y 60 $\mathrm{cm}$ de diámetro máximo (58,3\%). En menor frecuencia se encuentran siete fogones de tamaño grande con un diámetro mayor superior a $61 \mathrm{~cm}(29,2 \%)$. Solo tres fogones $(12,5 \%)$, tienen un diámetro máximo inferior a $30 \mathrm{~cm}$. La mayor frecuencia de fogones de tamaño mediano concuerda, aproximadamente, con el dato etnográfico aportado por Gusinde para los selk'nam, quién refiere que el hogar ...ocupa

1 El sitio de Marazzi 1 fue excavado inicialmente por Annette Laming-Emperaire y colaboradores (LamingEmperaire 1968, Laming-Enperaire et al. 1972). Con posterioridad el sitio fue evaluado mediante nuevos estudios estratigráficos por Flavia Morello (Morello et al. 1999). unos $50 \mathrm{~cm}$ de diámetro (Gusinde, 1982 [1931], p. 187). Estas referencias coinciden también con los datos mencionados por Annette LamingEmperaire en su diario de campo de diciembre de 1967, sobre las excavaciones realizadas junto al alero del bloque errático Marazzi 1. En los niveles superiores consigna que ...los fogones hasta aquí observados no superan los $60-70 \mathrm{~cm}$ de diámetro (Laming-Emperiare, 1965-68, p. 31)1.

Del conjunto de fogones se seleccionaron carbones pertenecientes a diez de éstos, que fueron sometidos a un estudio antracológico por la coautora y que son informados en este artículo. Este análisis se efectuó a partir de carbones provenientes de los sitios arqueológicos Marazzi 32 y Marazzi 38, situados en el litoral del fondo de bahía Inútil y sus carbones provienen de fogones de gran tamaño. Se analizaron también muestras de los sitios del interior: Tres Arroyos 1, Tres Arroyos 4 y Tres Arroyos 14, obtenidos de fogones de tamaño mediano (Fig. 1). Todos los sitios referidos están ubicados en el amplio valle de origen glacial que une bahía Inútil y bahía San Sebastián, en la zona norte de Tierra del Fuego ${ }^{2}$.

\section{MATERIAL Y MÉTODO}

Se efectuó una evaluación de los principales antecedentes ambientales y etnográficos de la zona norte de Tierra del Fuego a ser considerados en el presente trabajo y de la información de los contextos arqueológicos y sus dataciones calibradas, relacionadas con los sitios arqueológicos donde se obtuvieron las muestras de carbón sometidas a estudio.

El análisis antracológico comprendió ocho muestras de los sitios costeros Marazzi 38 (fogón $\mathrm{N}^{\circ} 20$ ) y Marazzi 32 (Fogones $\mathrm{N}^{\circ} 16,17,18$ y

2 En las localidades de Marazzi y Tres Arroyos se realizaron evaluaciones tafonómicas que contribuyeron a una mejor interpretación de los contextos arqueológicos en estudio (Borrero, 2003; Borella, 2003; Bahamondes, 2004; Martin, 2006; Torres, 2007; Borrero et al. 2009, entre otros). 


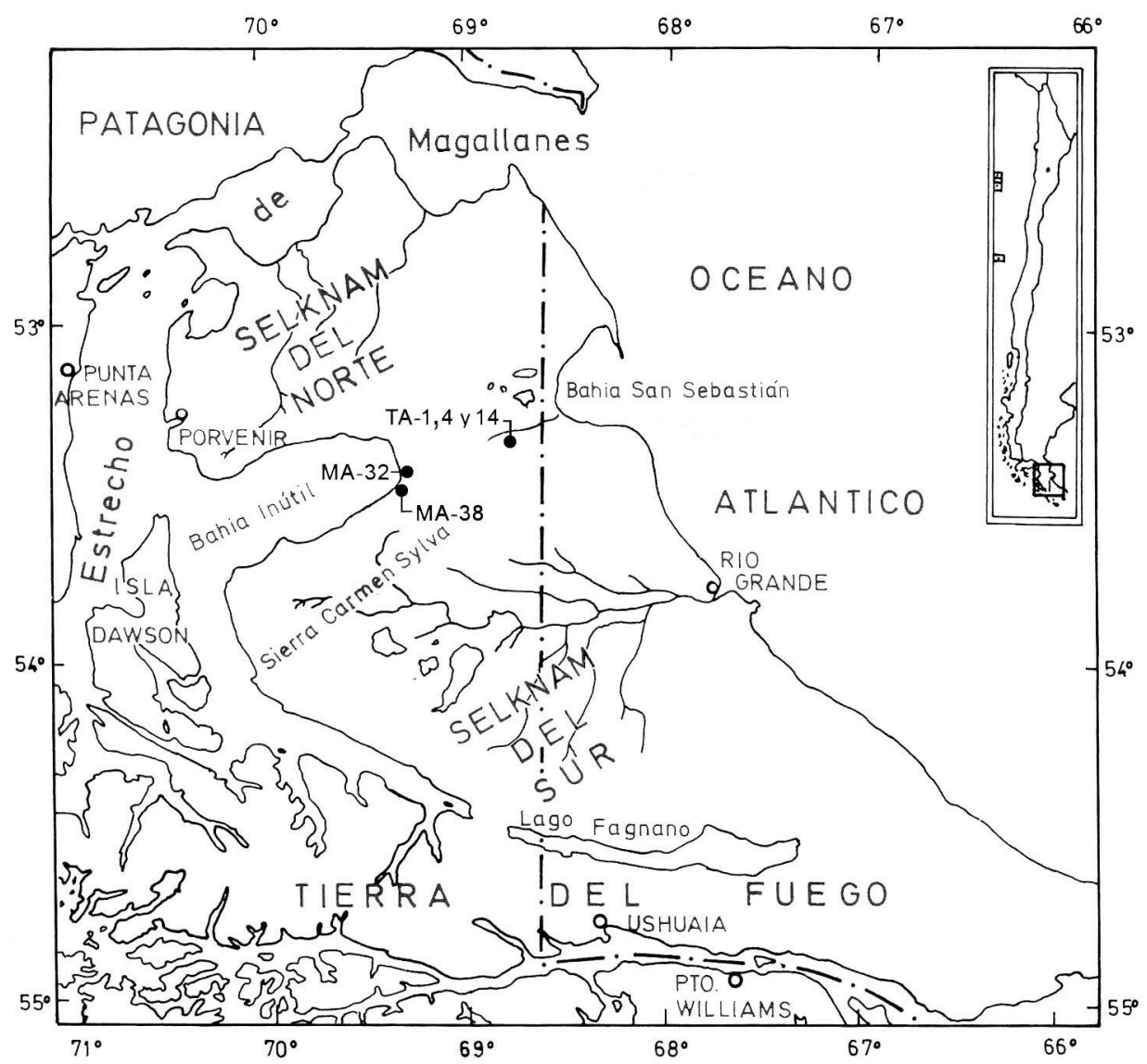

Fig. 1. Ubicación de los sitios arqueológicos correspondientes a los fogones estudiados.

19), situados en el fondo de bahía Inútil (Solari, 2005) y ocho muestras de carbones recuperados de los sitios Tres Arroyos 1 (fogones $\mathrm{N}^{\circ} 1$ y $\mathrm{N}^{\circ} 8$ ), Tres Arroyos 4 (fogón $\mathrm{N}^{\circ} 11$ ) y Tres Arroyos 14, impronta 88 (fogones $\mathrm{N}^{\circ} 12$ y $\mathrm{N}^{\circ} 13$ ) ubicados en el cerro de Los Onas.

Los carbones fueron identificados con un microscopio óptico Olympus BX60, en el Laboratorio de Estudios Arqueobotánicos e Historia Ambiental, perteneciente al Instituto de Estudios Antropológicos (UACh). La identificación anatómica se sustentó en una colección de referencia de maderas carbonizadas pertenecientes al Laboratorio y bibliografía especializada (Wagemann, 1949; Rancusi et al. 1987; Solari, 1993, entre otros).

El análisis se centró en la identificación anatómica de los carbones, la descripción de sus caracteres morfológicos (forma, tamaño, intrusiones de materias exógenas tales como cristales y pátinas). De manera preliminar se consignaron sistemáticamente las muestras que presentan posibles cristales adosados a los caracteres anatómicos de los carbones.

\section{ANTECEDENTES AMBIENTALES}

Los sitios estudiados se encuentran fitogeográficamente insertos dentro de la estepa fuego-patagónica, dominio de las planicies orientales, que posee un clima de estepa fría, BSk', siendo su formación característica la de Festuca gracillima, como un elemento importante y reiterativo del estrato herbáceo xérico (Pisano, 1977; Markgraf, 1993). En sectores donde las precipitaciones se aproximan a los $350 \mathrm{~mm}$ la estepa posee un componente arbustivo constituido principalmente por el matorral achaparrado de Chiliotrichum diffusum (romerillo), asociado a otras especies leñosas de áreas aledañas a los 
bosques de Nothofagus deciduo (lenga y/o ñirre), tales como Baccharis patagonica. Por su parte, el matorral de Lepidophylum cupressiforme situado entre las bahías Inútil y San Sebastián, posee una altura de 0.5 a $1.4 \mathrm{~m}$ y se encuentra acompañado de Berberis buxifolia y B. empetrifolia (Moore, 1983).

La síntesis efectuada por Markgraf (1991), basada en investigaciones geológicas, climáticas y polínicas, sugiere que en los últimos 3.000 años ha existido un aumento efectivo de la humedad y estaciones más marcadas, lo que se reflejaría en un clima con una mayor variabilidad, que implica un mosaico de diferentes tipos de vegetación para la región fuego-patagónica.

Los resultados del análisis de un perfil polínico efectuado en la localidad de Tres Arroyos, muestran que no existió bosque en la zona desde por lo menos 6.230 90 años AP (Beta 107938) (7.2936.803 años cal. AP) y que habrían predominado las gramíneas durante todo el Holoceno tardío. Otro perfil de polen realizado en la localidad de Marazzi, indica que desde 8.340 70 años AP (Beta 122859) (9.470-9.038 años cal. AP) y hasta el Holoceno tardío predominan las gramíneas y hay escasa presencia de polen de Nothofagus sp. Ambos perfiles muestran un registro preferente de taxones herbáceos que corresponden a una vegetación propia de estepa patagónica (Rojas, 1999).

Todos los sitios se encuentran actualmente en un ambiente estepario y la problemática antracológica está relacionada con la identificación y procedencia de los taxones. La vegetación arbustiva más frecuente en el sector de Tres Arroyos es el romerillo, (Chiliotrichum diffusum), acompañado con menor representación por Berberis sp. (Dollenz, 1991). Un estudio posterior de la vegetación actual, efectuado en la misma localidad, mostró que solo el $10 \%$ del total de especies de la localidad es leñosa. No obstante, el material arbustivo ocupa el $70 \%$ de la superficie de $1 \mathrm{~km}^{2}$ y está compuesto por Berberis buxifolia, Ribes magellanicum, Empetrum rubrum y Chiliotrichum diffusum. De éstos, Chiliotrichum diffusum tiene una cobertura del $70 \%$ del matorral arbustivo y dispone de ramas secas adecuadas para ser usadas como combustible (Rojas, 1998).

En el sector de Marazzi, domina también un ambiente estepario. Sin embargo, en la actualidad se observan escasos parches de bosque en el sector alto del río Marazzi, en la sierra Carmen Sylva, a una distancia de unos $12 \mathrm{~km}$ de los sitios arqueológicos estudiados, que se encuentran cercanos a la desembocadura del mismo río.

\section{ANTECEDENTES ETNOGRÁFICOS}

La revisión de los antecedentes etnográficos permite afirmar que el fuego tenía una importancia central en el sistema de vida selk'nam, tanto en lo cotidiano como en aspectos simbólicos y de organización social. Todo campamento, de corta o de larga permanencia, necesitaba del fuego para proporcionar calor al grupo familiar en su vivienda, asar la carne y preparar distintos artefactos (Fig. 2). Se utilizaba también para secar las pinturas corporales recién aplicadas (Segers, 1891; Gallardo, 1910; Beauvoir, 1915; Lotrhop, 1928; Gusinde, 1982 [1931]; Chapman, 1986; Coiazzi, 1997; Bridges, 2000; De Agostini, 2005 [1956], entre otros).

En los bosques del sur de Tierra del Fuego, los selk'nam podían aprovisionarse con gran facilidad de leña proveniente de troncos y ramas de especies arbóreas. En la estepa de la zona norte, los selk'nam disponían solo en forma ocasional de leña de árboles y acampaban en sectores próximos a arbustos, que eran aprovechados como combustible. El fuego tenía una notoria presencia en el paisaje, en especial en los campamentos situados en los amplios espacios esteparios septentrionales. El humo que generaba era utilizado como un sistema de señales para comunicarse con miembros del grupo que se encontraban a distancia o bien para avisar de algún acontecimiento a otros grupos vecinos, como en el caso del varamiento de una ballena que concitaba el encuentro de personas de distintos territorios locales, Haruwen. El fuego era ocupado también mediante antorchas para cazar aves en los acantilados o en las lagunas (Gallardo, 1910; Gusinde, 1982 [1931]; Chapman, 1986).

En los rituales de iniciación selk'nam el fuego ocupaba el lugar central en la gran cabaña durante la ceremonia del Hain, con sus espacios secretos para los hombres y los jóvenes iniciados, y los espacios públicos donde participaban también las mujeres. Shoort y Xalpen, los espíritus principales del Hain, surgían desde el inframundo a través del 


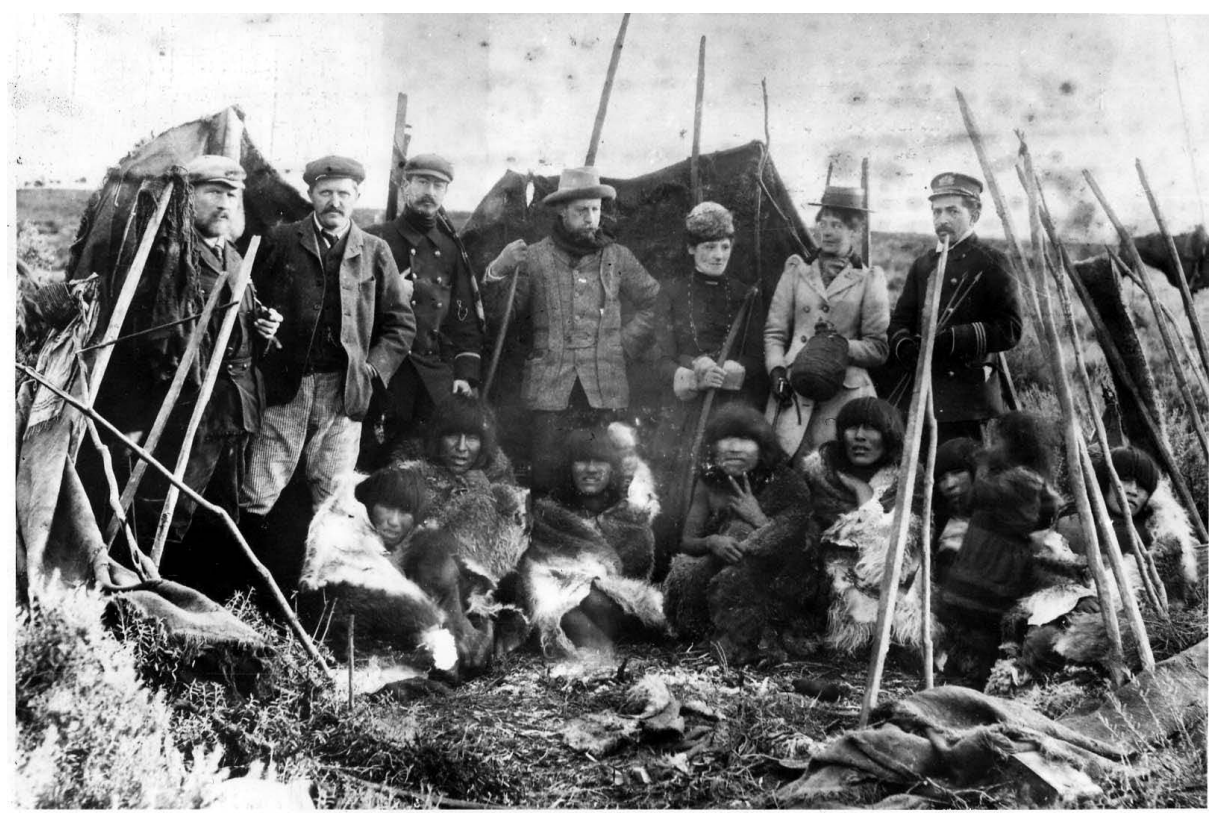

Fig. 2. Grupo selk'nam y europeos en paraviento del norte. Se observa un fogón de tamaño mediano, en la parte central de la fotografía. Bahía Gente Grande 1899.

Album de Rodolfo Stubenrauch. Archivo Fotográfico-Histórico: Centro de Estudios del Hombre Austral, Instituto de la Patagonia, Universidad de Magallanes.

fuego de la gran cabaña. Esta ceremonia constituía en su conjunto el eje cultural y psicológico del mundo selk'nam (Chapman, 1986).

\section{LOS SITIOS ARQUEOLÓGICOS Y LOS FOGONES ANALIZADOS}

\section{Sitios costeros}

En el presente estudio se consideran: el sitio Marazzi 32 (53 `28' S - 69 19' O), ubicado en el fondo de la bahía Inútil, junto a la orilla sur del río Marazzi y en las proximidades de su desembocadura, a $70 \mathrm{~m}$ de la línea de marea alta

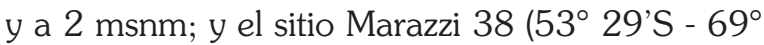
19'O), localizado a unos $2 \mathrm{~km}$ al sur de Marazzi 32 , situado sobre una terraza de $1 \mathrm{msnm}$ y a una distancia horizontal de cinco metros con respecto a la línea de alta marea (Massone \& Morello, 2007; Massone, 2017).

\section{Marazzi 32}

En la superficie del yacimiento, sobre una berma de playa, se identificaron seis conjuntos de restos óseos de cetáceos en superficie (Borella,
2003) y un séptimo durante el proceso de excavación (Massone, 2017). Estos conjuntos, que incluyen también restos de otras especies, se extienden por una superficie aproximada de 300 $\mathrm{m}^{2}$ (Fig. 3). En los años 2002 y 2004 se realizaron dos excavaciones de $8 \mathrm{~m}^{2}$ en total (cuadrículas $16 \mathrm{E}$ y 16D) que permitieron estudiar los restos de un gran fogón que formaba una extensa área de quema $\left(\mathrm{N}^{\circ} 17\right)$, con una gran extensión de cenizas y algunos restos de carbón, sin solución de continuidad. Esta área presenta límites irregulares y una extensión mayor a $381 \mathrm{~cm}$, con una potencia máxima de $16 \mathrm{~cm}$. A dicha área de quema se encontraron vinculados restos de cetáceo, guanaco (Lama guanicoe), pinnípedos (Otaria flavescens y Arctocephalus australis) y Aves, junto a artefactos líticos entre los que se cuentan raspadores y grandes rodados astillados con filos naturales amplios. Entre los restos de cetáceo del gran fogón $N^{\circ} 17$ destacan fragmentos con corte perimetral, perforaciones circulares y otras modificaciones artificiales (Massone \& Morello, 2007). Una muestra obtenida del mismo aportó una datación AMS de 635_35 años AP, (661 a 520 años cal. AP). Superpuestos al gran fogón $\mathrm{N}^{\circ} 17$, se identificaron dos fogones restringidos 
( $\mathrm{N}^{\circ} 18$ y 19), ambos de forma subcircular alargada y que se diferenciaban claramente del fogón $\mathrm{N}^{\circ} 17$ por su color más oscuro, gris negro. El fogón $\mathrm{N}^{\circ} 18$ presentaba un diámetro máximo de $38 \mathrm{~cm}$ y una potencia de $8 \mathrm{~cm}$, en tanto que el diámetro máximo del fogón $\mathrm{N}^{\circ} 19$ era superior a $55 \mathrm{~cm}$ y tenía una escasa potencia $(2 \mathrm{~cm})$. Una muestra procedente del fogón $\mathrm{N}^{\circ} 18$, superpuesto al área del fogón $\mathrm{N}^{\circ} 17$, dio una datación AMS de $560 \pm 35$ años AP (635 a 491 años cal. AP), constituyéndose en la prueba más confiable de un evento posterior de combustión (Massone \& Morello, 2007).

Durante el año 2014 se comprobó que la acción del río Marazzi, debido a alguna fuerte crecida, había erosionado de manera notoria ese sector del sitio, llevándose todos los sedimentos de la cuadrícula 16D, buena parte de la cuadrícula $16 \mathrm{E}$ y de las cuadrículas adyacentes (Massone, 2017).

En el año 2004 se excavó también la cuadrícula $13 \mathrm{H}$, que coincide con una importante concentración de huesos de cetáceo, detectados en superficie. Dicha cuadrícula presentó numerosos restos óseos de cetáceos de gran tamaño, varios de los cuales mostraron evidencias de modificaciones artificiales. Junto a estos restos se encontraron conchas marinas, fragmentos óseos de guanaco, lobo marino y otras especies. Destacan algunos cortes perimetrales en huesos de guanaco. Se localizaron dos puntas líticas, una pedunculada con aletas

Fig. 3. Planta del sitio Marazzi 32. Fogones, señales de fuego en artefactos o en restos óseos y conjuntos óseos de cetáceo, identificados antes de la erosión del sector oriental del sitio, ocasionada por el río Marazzi y observada en 2014 (Dibujo de Flavia Morello, modificado por Roxana Torres).

3 Fecha calibrada usando la Mediana. largas y otra apedunculada, algunas raederas y otros artefactos líticos. En esta cuadrícula se encontró otro gran fogón, el $\mathrm{N}^{\circ} 16$, con un diámetro mayor superior a $240 \mathrm{~cm}$. Una muestra de carbón aportó una datación convencional de 670+100 AP, 608 años cal. AP $^{3}$ (Massone \& Morello, 2007).

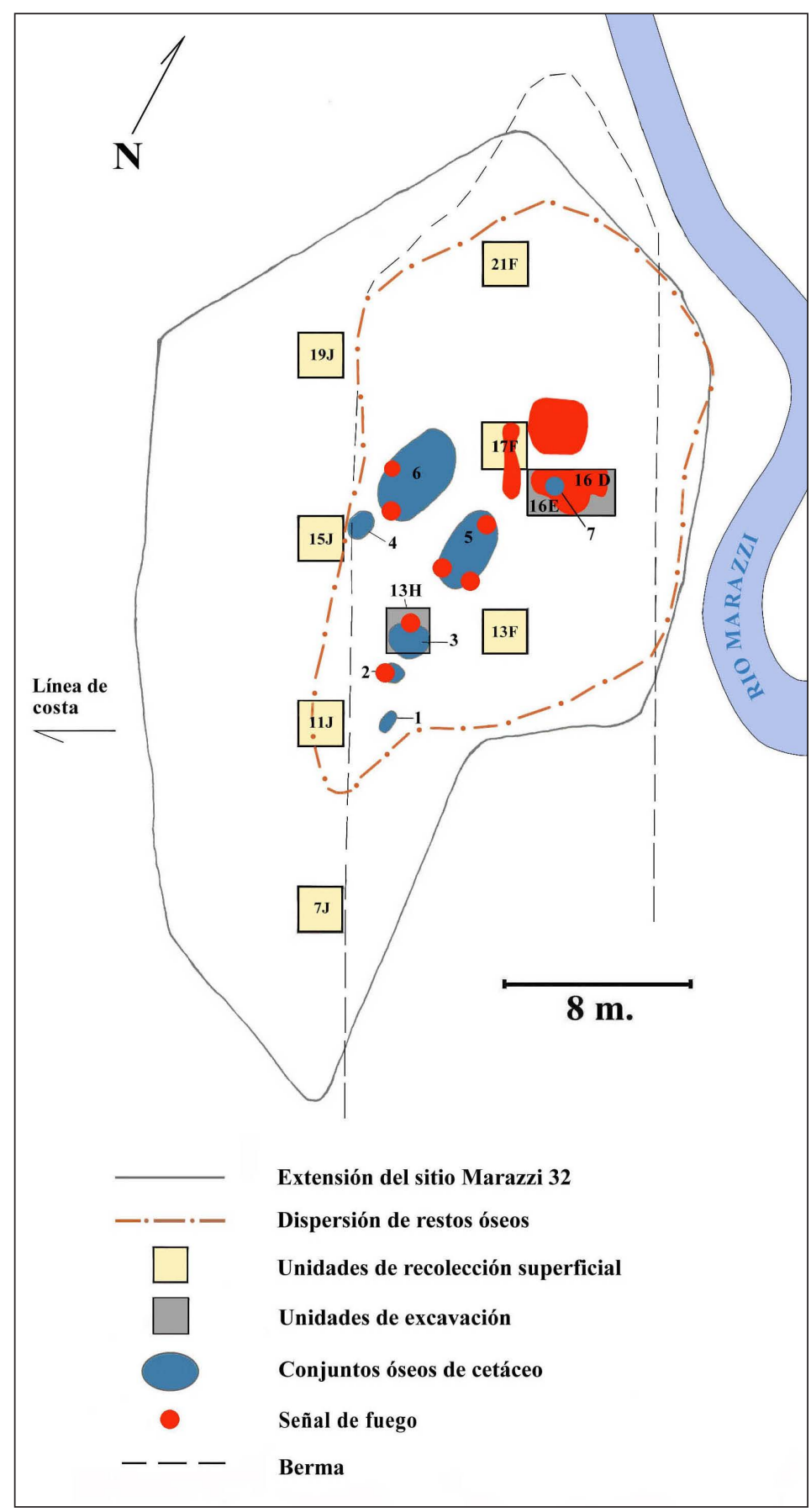




\section{Marazzi 38}

Corresponde a un conjunto de tres basurales conchíferos contiguos dispuestos en una terraza baja, con presencia de restos óseos de cetáceos, junto a otros restos fáunicos y líticos. En el año 2003 se realizó un sondeo en el basural №2 del sitio de $1 \mathrm{~m}^{2}$. En el sondeo se localizó una vértebra grande de ballena en estratigrafía, asociada a un gran fogón, el $\mathrm{N}^{\circ} 20$, de un diámetro máximo superior a $100 \mathrm{~cm}$ y una potencia de $15 \mathrm{~cm}$. Se encontró vinculado a un basural conchífero de choritos (Mytilus chilensis) y mauchos (Nacella magellanica), a restos de peces, aves y guanaco (Massone \& Morello, 2007). Una muestra de carbón procedente del fogón fue datada mediante AMS, dando una fecha de $795 \pm 35$ años AP (767 a 567 años cal. AP). Una observación realizada en 2011 permitió constatar que la acción del mar habría arrasado el basural conchífero $\mathrm{N}^{\circ} 3$ del sitio, detectado en el año 2003, cubriendo el lugar con depósitos de arena (Massone, 2017).

\section{Sitios del Interior}

La localidad de Tres Arroyos, y específicamente el cerro de Los Onas $\left(53^{\circ} 21^{\prime} \mathrm{S}\right.$ - $\left.68^{\circ} 48^{\prime} \mathrm{O}\right)$, se ubican a unos $20 \mathrm{~km}$ al sur oeste de la bahía San Sebastián. En este cerro y en sus faldeos se han identificado diferentes abrigos rocosos entre los que se cuentan la pequeña cueva Tres Arroyos 1 y el alero Tres Arroyos 4. Se han identificado además restos de un campamento al aire libre, denominado Tres Arroyos 14 (Fig. 4), donde se han excavado en forma amplia las llamadas improntas 88 y 89 , postuladas como restos de viviendas selk'nam (Massone et al. 1993; Massone, 2017).

\section{Tres Arroyos 1}

La cueva Tres Arroyos 1 está ubicada en la parte inferior de la ladera norte del cerro de Los Onas, a una cota de 92 msnm. Su entrada está orientada en dirección noroeste y norte, y domina el amplio valle que une bahía Inútil y bahía San Sebastián. La Cueva Tres Arroyos tiene un tamaño de 8,30 m de frente y 8,30 m de fondo y 3,90 $\mathrm{m}$ de altura en la parte máxima.
Entre los años 1981 y 1999 se llevaron a cabo diferentes campañas de excavación que abarcaron una superficie total de $20 \mathrm{~m}^{2}$. En los depósitos profundos del yacimiento se localizaron cinco fogones en cubeta correspondientes a las ocupaciones de cazadores-recolectores tempranos durante la transición PleistocenoHoloceno, con presencia de variados artefactos líticos, óseos, restos de colorante y de fauna tanto extinta como moderna, con fechas confiables $C^{14}$ que oscilan entre 10.130 y 10.855 años $\mathrm{AP}$, que corresponden a un rango comprendido entre 11.706 y 12.718 años cal. AP (Massone, 2004, 2010).

Sus niveles superiores poseen a lo menos cuatro eventos de ocupación humana, cuyos restos han quedado depositados en sedimentos arenosos de los estratos IV, III, II y I, respectivamente. Éstos corresponden a la presencia de grupos selk'nam y posiblemente de sus antecesores, durante los últimos 1.400 años. En estos depósitos del sitio predominan entre los artefactos líticos las puntas pedunculadas, raspadores frontales pequeños, raederas laterales de borde convexo o recto y algunos cuchillos. Las puntas de cuerpo triangular ancho con pedúnculo basal, características de los niveles IV y III, tienden a ser reemplazadas por puntas más pequeñas de cuerpo y pedúnculo más fino en el estrato I y que, morfológicamente tienen correspondencia con el registro etnográfico de las puntas selk'nam de tamaño reducido. En los niveles superiores del sitio también son frecuentes pequeños fragmentos de colorante rojo y la presencia de algunos artefactos óseos que corresponden a punzones y cuentas de collar cilindricas en huesos de aves, destacando en el estrato IV un colgante en diente de Lama sp., con incisión circular próxima a su extremo superior (Massone et al. 1993). Se encuentran también variados restos óseos de guanaco, entre otros, con huellas de estadios de procesamiento primario, secundario y consumo final (Muñoz, 2000).

En los niveles superiores se localizaron en total nueve fogones. Los fogones números 1, 2, 3 y 9 en el estrato II, los fogones números 4, 5, 6 y 8 en el estrato III y el fogón $N^{\circ} 7$ en el estrato IV. Se analizaron carbones de los fogones $\mathrm{N}^{\circ} 1$ y $\mathrm{N}^{\circ} 8$. El fogón $N^{\circ} 1$ fue excavado en 1997 en el sector E de la cueva. Aunque el estrato II donde se sitúa 
dicho fogón no ha sido aún datado, debería ser más reciente que 700 años $\mathrm{AP}$, fecha que corresponde a una datación obtenida del estrato III, inferior. El fogón $\mathrm{N}^{\circ} 8$ se localizó en el sector del contacto A-B, en el estrato III, que fue fechado en $700 \pm 70$ años AP (767 a 506 años cal. AP).

\section{Tres Arroyos 4}

El sitio se ubica en la parte alta del Cerro de Los Onas, en la cota de $116 \mathrm{msnm}$. Se trata de un alero rocoso cuyo frente se orienta en dirección norte y domina el valle que une bahía Inútil con bahía San Sebastián. Su tamaño es de 9,90 m de frente, 3,30 m de fondo y 1,90 $\mathrm{m}$ de altura en la parte máxima.

En 1992 se realizó un sondeo estratigráfico de $1 \mathrm{~m}^{2}$ (cuadrícula 3E), hacia el centro del alero (Massone et al. 1993). En 1996 se efectuaron dos nuevas cuadrículas de $1 \mathrm{~m}^{2}$ cada una (3C y 4C), al oeste de la primera (Morello et al. 1997). En la cuadrícula $3 \mathrm{E}$ se distinguieron dos componentes estratigráficos. El inferior, entre 20 y $40 \mathrm{~cm}$ de profundidad, con presencia de una punta triangular apedunculada, un micro raspador y desechos de talla lítica; abundantes restos de aves, fragmentos óseos de guanaco, zorro (Lycalopex sp.), roedores y moluscos; restos de un fogón $\left(\mathrm{N}^{\circ} 11\right)$ y de pigmentos colorantes. El fogón fue datado en $130 \pm 30$ años AP (279 a 0 años cal. AP, Mediana: 93 años cal. $\mathrm{AP})^{4}$. En los 20 centímetros superiores del depósito se identificó un segundo componente cultural, con un desecho de vidrio, una posible preforma de punta selk'nam, restos líticos de talla, fragmentos de guanaco, oveja (Ovis aries), aves, zorro y coruro (Ctenomys magellanicus). En este componente se encontraron restos de un lente que corresponde al fogón $\mathrm{N}^{\circ} 10$ (Massone, 2017).

\section{Tres Arroyos 14}

En el faldeo del Cerro de Los Onas se localizaron entre 1986 y 1990, un total de 304 oquedades o depresiones en la superficie. Se estimó que por formas que variaban de circular a elipsoidal, por diferencias en el tamaño de las oquedades, cambios en la cubierta herbácea y contenido cultural superficial, una parte de dichas depresiones podrían corresponder, a fondos de viviendas selk'nam. Se postuló que existirían tres categorías de oquedades: improntas hechas por humanos y utilizadas culturalmente como fondos de viviendas temporales; oquedades de origen natural, aprovechadas o modificadas por los humanos y utilizadas culturalmente; oquedades de origen natural sin uso cultural (Massone et al. 1993). El estudio vegetacional realizado por el botánico Orlando Dollenz, puso de manifiesto que las oquedades se encuentran insertas en dos comunidades diferenciadas: pastizal del cerro, dominado por musgos y Poa sp. y matorral de romerillo, asociado con una alta proporción de coirón, Festuca gracillima. Sin embargo, la composición florística de las oquedades se diferencia de la matriz vegetacional circundante, dominando en cada una de esas unidades la presencia de Azorella trifurcata, a causa de una acción preferentemente antrópica (Dollenz, 1991). Los estudios espaciales y estratigráficos realizados permiten postular que una parte de las oquedades y en particular las improntas 88 y 89 , que fueron sometidas a excavaciones arqueológicas ampliadas con finos registros de materiales en planta, corresponderían al sitio Tres Arroyos 14, restos de un campamento selk'nam de uso reiterado en el tiempo (Massone et al. 1993). En relación al origen de dichas oquedades, recientes estudios geoarqueológicos en el lugar han permitido proponer un origen natural para estas depresiones (Ozán \& Borrero, 2017). Lo anterior no inhibe la posibilidad de su uso cultural, como lo demuestran los contextos arqueológicos asociados a fogones estudiados en las depresiones o improntas 88 y 89.

Entre 1990 y 1992 se efectuaron sondeos estratigráficos en 20 improntas. De éstas, 14 presentaron evidencias culturales (fauna, material lítico, esquirlas de vidrio, metal, colorante rojo y restos de carbón), cuatro de carácter dudoso y dos no presentaron restos culturales. La excavación ampliada de las improntas $\mathrm{N}^{\circ} 88$ y $\mathrm{N}^{\circ} 89$, demostraron corresponder a fondos de habitación con restos de fogones y materiales culturales asociados y dataciones, compatibles con la ergología selk'nam. 


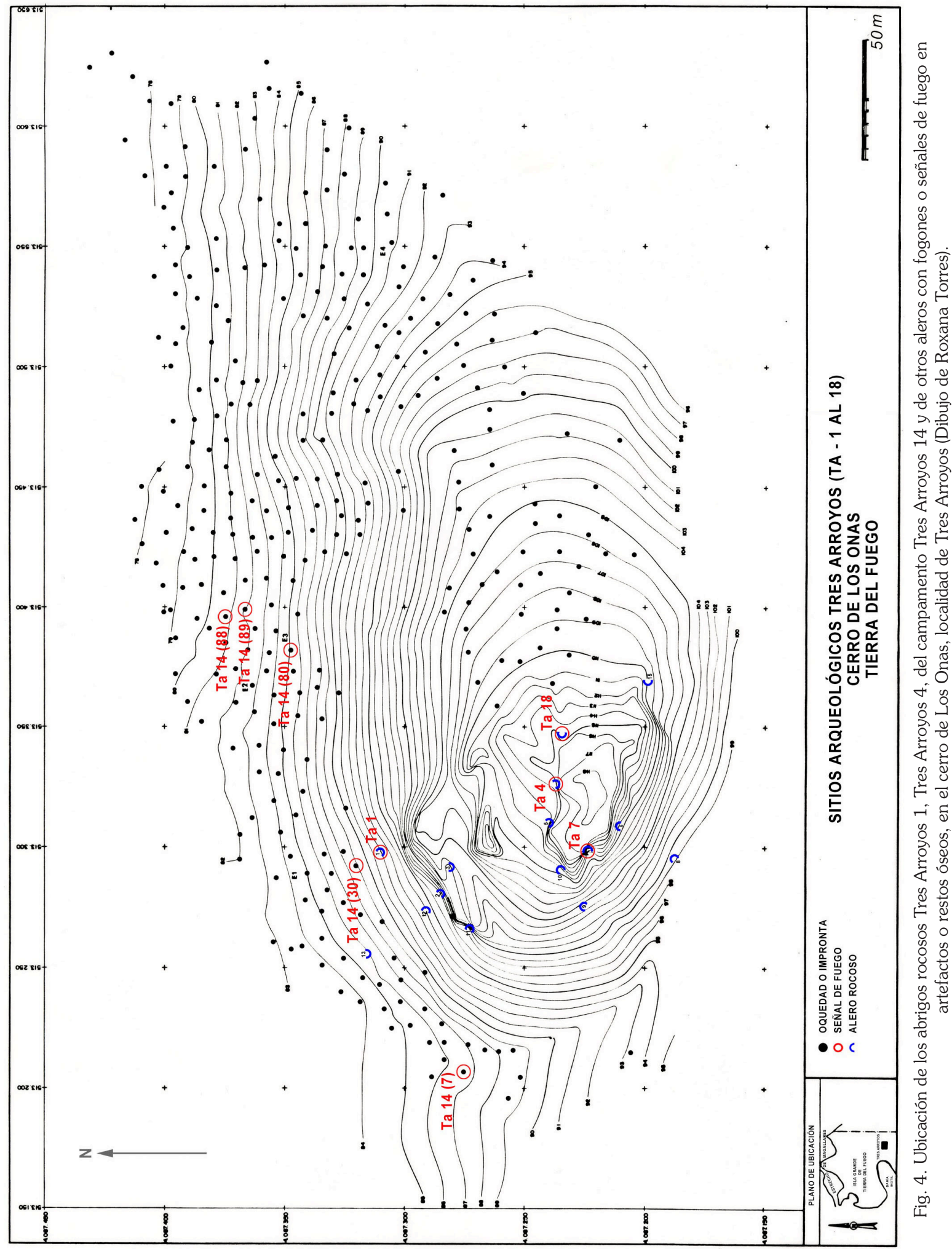


Se encontraron dos fogones asociados a la impronta $\mathrm{N}^{\circ} 88$, que corresponden a los $\mathrm{N}^{\circ} 12$ y 13 del estudio general. El fogón $\mathrm{N}^{\circ} 12$ fue datado en $220 \pm 30$ años AP (313 a 0 años cal. AP; Mediana: 194 años cal. AP) ${ }^{5}$. El hallazgo de una lezna metálica $y$ un pequeño desecho de vidrio verde al interior del depósito del fondo de habitación, refuerza la idea de su pertenencia a una ocupación del período histórico de contacto con grupos occidentales. El fogón $N^{\circ} 13$ aportó la datación de $170 \pm 30$ años AP (285 a 0 años cal. AP; Mediana: 128 años cal. AP) ${ }^{6}$ En la impronta 89 se localizó un gran fogón $\mathrm{N}^{\circ} 14$, con presencia de abundantes lascas en vidrio, una pieza metálica, artefactos líticos, colorantes y restos de fauna, entre la que destaca guanaco. El conjunto fue datado en $280 \pm 70$ años AP, 494 a 0 años cal. AP; Mediana: 292 años cal. AP (Massone et al. 1993).

\section{ANTRACOLOGÍA DE LOS FOGONES}

\section{Sitios costeros}

La identificación de 162 carbones pertenecientes a ocho muestras de los sitios Marazzi 38 y Marazi 32 se comportan, a nivel de presencia-ausencia de taxones, de manera similar. Las distinciones más significativas en los carbones corresponden a los porcentajes de muestras del tipo arbóreo con respecto al arbustivo.

En Marazzi 38 la diferencia es significativa entre los taxones arbustivos, que predominan $(59,4 \%)$ y los arbóreos con una representación menor (36,5\%) (Fig. 5). En Marazzi 32 los carbones pertenecientes al género arbóreo Nothofagus, del tipo caduco, lenga y/o ñirre, alcanzan escasa predominancia $(45,5 \%)^{7}$. Con una presencia similar pero ligeramente inferior $(44,3 \%)$, se encuentran los carbones de taxones arbustivos tales como romerillo, especie siempre dominante, parrilla, chilco, canelo, ${ }^{8}$ Berberis tipo calafate, ericácea

5 Datación efectuada mediante el aporte del proyecto FONDECYT 1140939 (Beta-377641).

6 Dataciones AMS, no publicadas, realizadas a partir de sedimentos carbonosos de ambos fogones mediante el aporte del proyecto Fondecyt 1140939 (Muestra fogón 12, Beta 377641, año 2014; muestra fogón 13, Beta 409900, año 2015).

7 Para fines comparativos es de interés mencionar el estudio de los contextos de los sitios Ewan I y Ewan II en el ambiente tipo chaura y compuesta tipo Baccharis (Fig. 6).

El análisis antracológico da cuenta de ciertos elementos básicos en los sitios de bahía Inútil: 1.- Complementariedad en el uso de especies arbustivas y especies arbóreas en todas las muestras, a excepción de la muestra 3 (MA 38) que sólo cuenta con dos fragmentos de carbón. 2.Diferencia en las características de los carbones. Las muestras que poseen carbones friables son de difícil determinación anatómica (MA 38, sondeo 1: nivel 5; MA 32, cuadrícula 16E: nivel 1), mientras que otras poseen una anatomía limpia, brillante y por tanto fácilmente identificables (MA 32 , cuadrícula $13 \mathrm{H}$ : nivel 1 ). Ciertas muestras solamente poseen superpuestos a su anatomía estructuras geométricas correspondientes posiblemente a cristales (MA 38, sondeo 1: niveles 1 y 2). 3.- Diferencias en el tamaño de los fragmentos. Mientras que los carbones de Nothofagus se caracterizan por tener mayor tamaño, lo que facilita su identificación (MA 38, sondeo 1: nivel 2), las muestras de especies arbustivas corresponden a fragmentos menores, de diámetros reducidos, muchas veces con anatomía alterada, nudos y pátinas propias de la intrusión de sedimento en su estructura anatómica, que dificultan su identificación específica (MA 38, cuadrícula $13 \mathrm{H}$ : nivel 1). A modo de ejemplo, son frecuentes los fragmentos de romerillo que presentan anillos de crecimiento, finos $y$ numerosos, equivalentes a un rango de edad de los arbustos entre 8 y 14 años, en diámetros muy pequeños (3-4 mm).

\section{Sitios del interior}

Se han analizado ocho muestras de carbones recuperados de los sitios Tres Arroyos 1, 4 y 14. Para tal efecto se utilizó la misma metodología antracológica empleada con las muestras de los sitios costeros descritos anteriormente. La diversidad de

boscoso del sur de Tierra del Fuego, vinculados a estructuras de madera de filiación selk'nam (Mansur et al. 2007). El análisis antracológico ha mostrado el uso predominante de Nothofagus antarctica, ñirre, para la combustión en los fogones de ambos sitios (Caruso, 2014).

8 Como muchas especies de la región fuego-patagónica, Drimys winteri posee características tanto arbustivas como arbóreas, dependiendo de su exposición. 


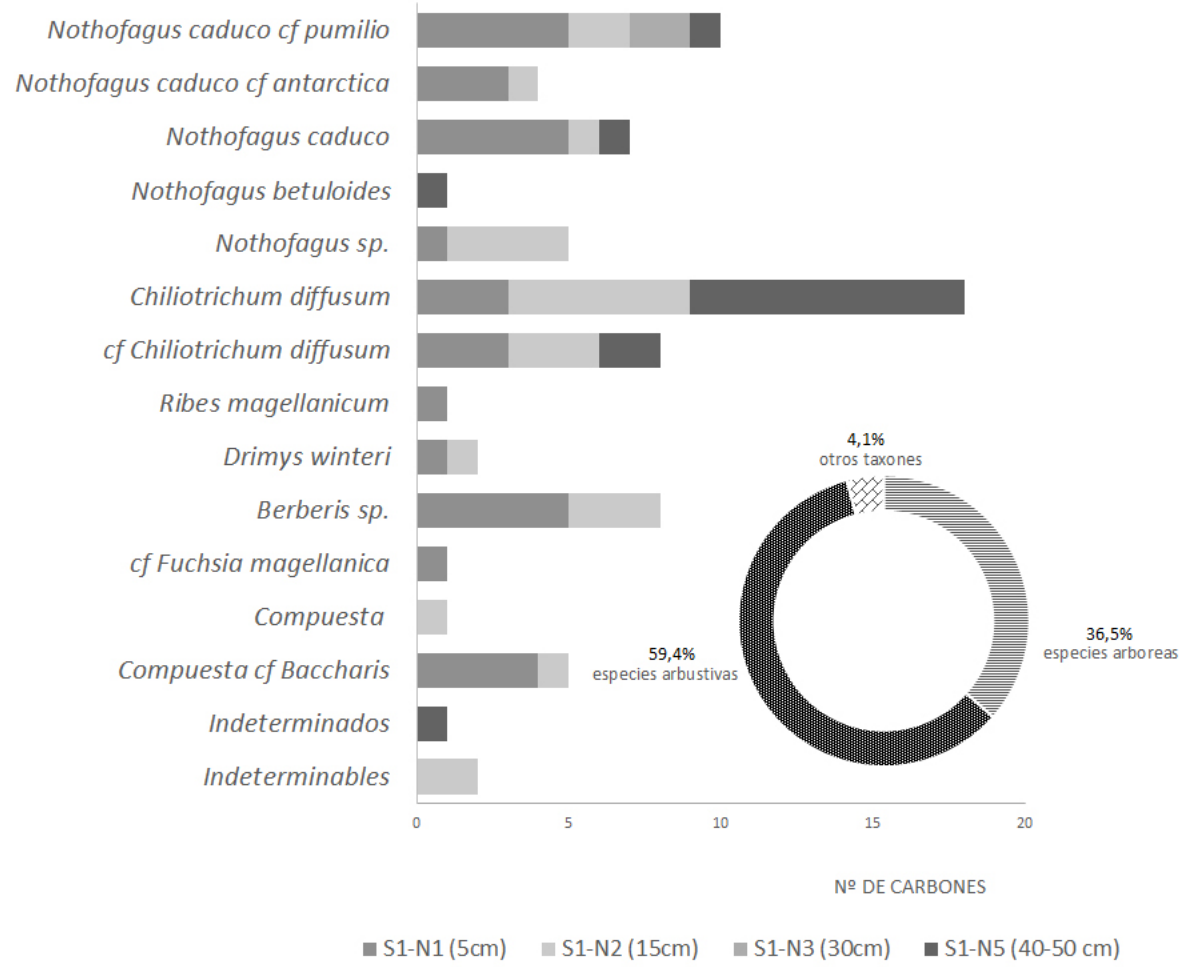

Fig. 5. Diversidad de taxones y tipos vegetales, sitio Marazzi 38 (Gráfico preparado por Alia Pichincura).

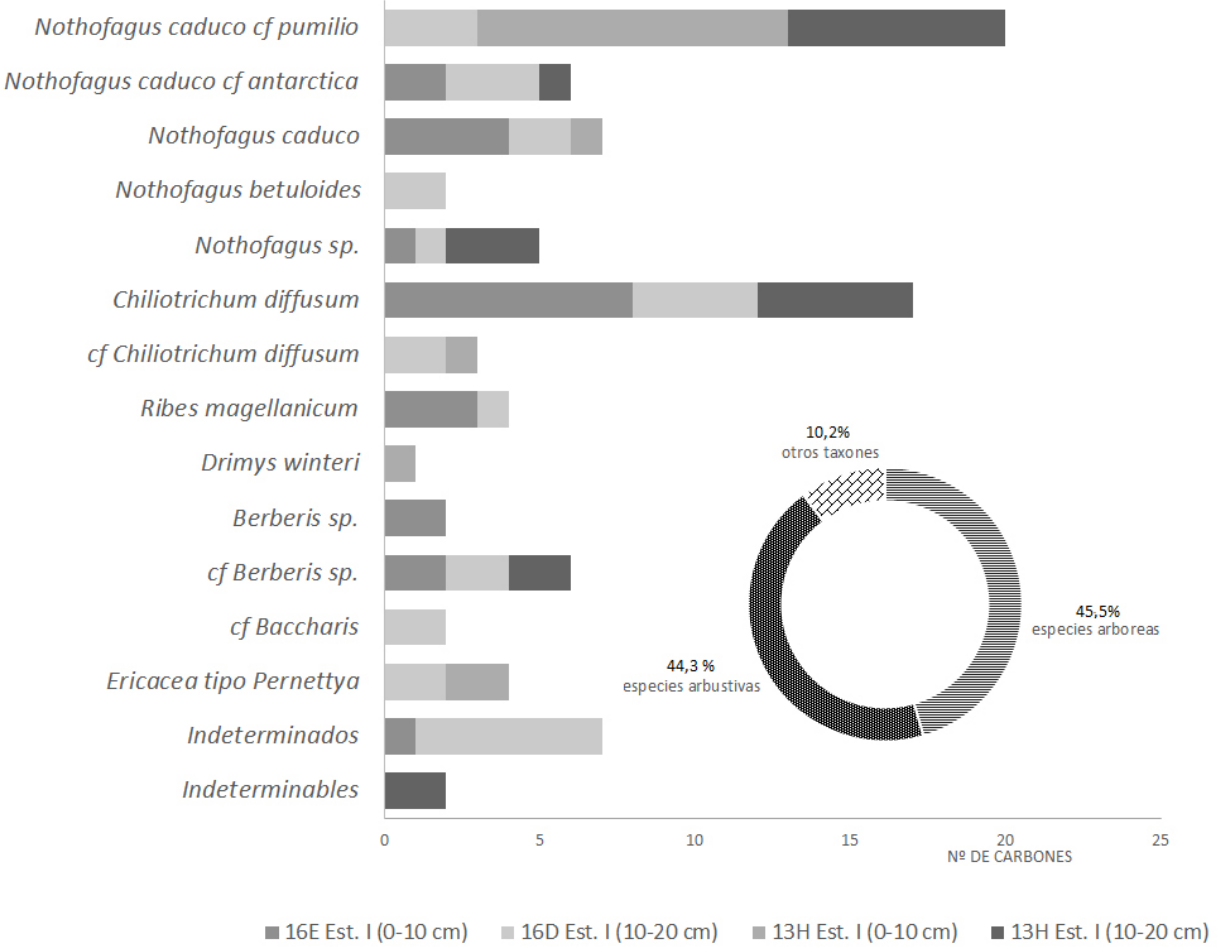

Fig. 6. Diversidad de taxones y tipos vegetales, sitio Marazzi 32 (Gráfico preparado por Alia Pichincura). 
Tabla 1. Resultados antracológicos, sitios Tres Arroyos 1, 4 y 14.

\begin{tabular}{|c|c|c|c|c|c|c|c|c|c|c|c|}
\hline $\begin{array}{c}\text { Sitios } \\
\text { Tres Arroyos } \\
1,4 \text { y } 14\end{array}$ & 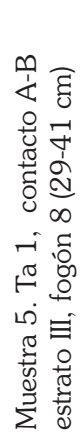 & 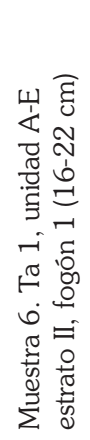 & 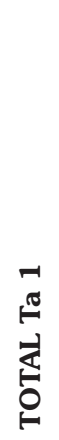 & 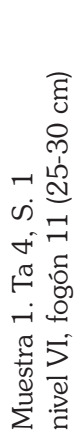 & 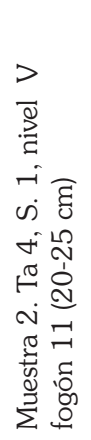 & 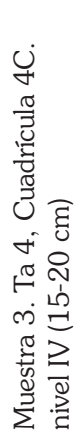 & 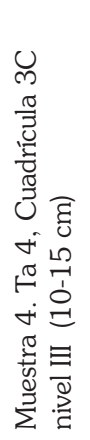 & 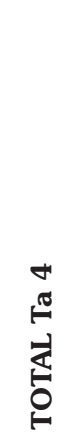 & 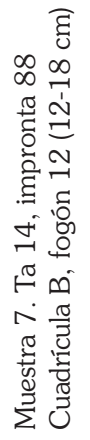 & 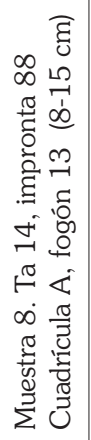 & 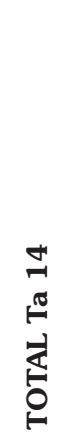 \\
\hline $\begin{array}{l}\text { Chiliotrichum } \\
\text { diffusum }\end{array}$ & 50 & 10 & 60 & 62 & 45 & 40 & 14 & 161 & 30 & 30 & 60 \\
\hline Berberis sp. & 0 & 4 & 4 & 9 & 3 & 0 & 1 & 13 & 0 & 0 & $\mathbf{0}$ \\
\hline Baccharis sp. & 1 & 0 & $\mathbf{1}$ & 0 & 0 & 0 & 0 & $\mathbf{0}$ & 0 & 0 & $\mathbf{0}$ \\
\hline cf. Baccharis sp. & 0 & 0 & $\mathbf{0}$ & 3 & 0 & 0 & 0 & 3 & 0 & 0 & $\mathbf{0}$ \\
\hline $\begin{array}{l}\text { Asteraceae } \\
\text { (Compositae) }\end{array}$ & 0 & 0 & 0 & 1 & 0 & 0 & 0 & $\mathbf{1}$ & 0 & 0 & 0 \\
\hline $\begin{array}{l}\text { Nothofagus sp. } \\
\text { (caduco) }\end{array}$ & 0 & 0 & 0 & 2 & 0 & 0 & 0 & 2 & 0 & 0 & 0 \\
\hline $\begin{array}{l}\text { Nothofagus } \\
\text { betuloides }\end{array}$ & 0 & 0 & 0 & 0 & 0 & 1 & 0 & 1 & 0 & 0 & 0 \\
\hline $\begin{array}{l}c f . \text { Ribes } \\
\text { magellanicum }\end{array}$ & 0 & 0 & $\mathbf{0}$ & 1 & 0 & 0 & 0 & 1 & 0 & 0 & 0 \\
\hline $\begin{array}{l}\text { Lebethantus } \\
\text { myrsinites }\end{array}$ & 0 & 0 & 0 & 0 & 0 & 0 & 1 & 1 & 0 & 0 & 0 \\
\hline Madera podrida & 0 & 0 & $\mathbf{0}$ & 0 & 0 & 1 & 0 & 1 & 0 & 0 & $\mathbf{0}$ \\
\hline $\begin{array}{l}\text { Carbón } \\
\text { cristalizado }\end{array}$ & 0 & 0 & 0 & 0 & 1 & 0 & 0 & 1 & 0 & 0 & 0 \\
\hline Indeterminables & 0 & 2 & 2 & 0 & 0 & 0 & 0 & $\mathbf{0}$ & 0 & 0 & $\mathbf{0}$ \\
\hline Total & 51 & 16 & 67 & 78 & 49 & 42 & 16 & 185 & 30 & 30 & 60 \\
\hline
\end{tabular}

sus fechados y la procedencia de lugares distintos del cerro, impide reunirlos e interpretarlos como una sola unidad. Sin embargo, se observa una homogeneidad en las especies, siendo preponderante la presencia del romerillo (Tabla 1).

Tres Arroyos 1

La muestra $\mathrm{N}^{\circ} 5$ proviene de la cueva Tres Arroyos 1 y corresponde al fogón $\mathrm{N}^{\circ} 8$, situado en el estrato III, del sector identificado como contacto A-B. En la muestra Chiliotrichum diffusum tiene una presencia dominante que alcanza al $98 \%$ del total de carbones, mientras que Baccharis representa el $2 \%$ restante.

La muestra $\mathrm{N}^{\circ} 6$ procede también de la cueva Tres Arroyos 1 y corresponde al fogón $N^{\circ} 1$, situado en el estrato II, en el sector denominado unidad A-E. Esta muestra no posee una cantidad significativa de carbones recuperados, alcanzando sólo a 16 fragmentos. Chiliotrichum diffusum tiene una presencia dominante, 10 fragmentos (62,5\%), mientras que Berberis sp. está representado por cuatro fragmentos, no pudiéndose identificar las dos muestras restantes, debido a su mal estado de conservación. 
Tres Arroyos 4 (Ta 4)

En ambas muestras ( 1 y 2 ) del sitio Ta 4, obtenidas del fogón $\mathrm{N}^{\circ} 11$, predomina la presencia de fragmentos que corresponden a romerillo. En la muestra 1 (nivel de 25 a $30 \mathrm{~cm}$ ), Chiliotrichum diffusum alcanza un elevado porcentaje (79,5\%), seguido con menores representaciones por Berberis sp. (11,5\%), cf. Baccharis (3,8\%), Nothofagus sp. (2,6\%), compuesta (Asteraceae) $(1,3 \%)$ y cf. Ribes magellanicum (1,3\%). En este caso las especies arbustivas dominan con un $97,4 \%$, en relación a la escasa presencia de una especie arbórea (2,6\%). En la muestra 2, (20 a $25 \mathrm{~cm})$, Chiliotrichum diffusum es ampliamente dominante (91,8\%). Berberis sp. posee un escaso porcentaje de $6,1 \%$. Se suma además un carbón cristalizado no identificado (2,0\%).

La muestra 3, corresponde a 42 carbones dispersos recuperados en 1996 de la cuadrícula 4C, próxima a la cuadrícula $3 \mathrm{E}$ donde se localizaron los fogones $\mathrm{N}^{\circ} 10$ y 11, en la excavación inicial de 1992. Estos carbones no se encuentran concentrados en una estructura de combustión, sino que serían carbones dispersos producto de la limpieza de uno de los fogones. En este caso es más probable, por su profundidad, que pertenezcan al fogón superior $\mathrm{N}^{\circ} 10$. Por otra parte, también es posible que correspondan a carbones provenientes de otra estructura no detectada, que pudiera estar situada fuera de las cuadrículas excavadas en 1992 y 1996. La muestra $\mathrm{N}^{\circ} 3$ pone de manifiesto una presencia aún más dominante de romerillo, que alcanza el $95,2 \%$ de todos los fragmentos de carbón, en tanto que coihue, representa tan solo el $2,4 \%$ del total. Un fragmento de madera podrida de especie no identificada suma el 2,4\% restante. Por último, la muestra 4 , con un menor número de fragmentos, también corresponde a carbones dispersos que pueden tener una explicación similar a las alternativas expuestas para la muestra $\mathrm{N}^{\circ} 3$. La muestra $\mathrm{N}^{\circ} 4$ presenta 14 fragmentos de Chiliotrichum diffusum (87,5\%), sólo 1 muestra de Berberis sp. $(6,25 \%)$ y de Lebethantus myrsinites (murtilla).

Sitio Tres Arroyos 14

Tanto la muestra de carbones $\mathrm{N}^{\circ} 7$ procedente del fogón $\mathrm{N}^{\circ} 12$, como la muestra de carbones $\mathrm{N}^{\circ} 8$ que corresponde al fogón $\mathrm{N}^{\circ} 13$, del sitio Ta 14 , impronta 88, Chiliotrichum diffusum representa la única especie utilizada para la combustión de los fogones $N^{\circ} 12$ y 13.

\section{DISCUSIÓN Y CONCLUSIONES}

Considerando el conjunto de 24 fogones estudiados con anterioridad, referidos en la introducción (Massone, 2017) y los fogones de cinco sitios arqueológicos considerados en el presente trabajo, es posible proponer que las diversas características de los fogones de los selk'nam del norte y de sus antecesores inmediatos, están relacionadas con la variabilidad de sus asociaciones contextuales en cada sitio. En este sentido es importante considerar el emplazamiento del sitio, su funcionalidad, el sector o sectores del sitio donde están localizados los fogones y su relación con otros rasgos como los basurales conchíferos, o los basurales con huesos de guanaco o con restos de cetáceos, así como la relación entre estos factores y el tamaño del fogón o el número de fogones en cada sitio.

$\mathrm{Al}$ respecto debe tenerse presente que la redundancia de ocupación de un lugar, como ocurre por ejemplo en Marazzi 32 o en Tres Arroyos 1, genera procesos de palimpsesto de difícil lectura para el arqueólogo (Bailey, 2007). A esto se suma también la incorporación de restos por mezcla, producto de procesos geomorfológicos y tafonómicos. Los procedimientos finos de excavación y de registro de los datos contribuyen en gran medida a reconocer y a atenuar estos efectos de mezcla.

Considerando el conjunto total de fogones estudiados en el norte de Tierra del Fuego y el tamaño de éstos, se ha sugerido que los fogones de tamaño pequeño a mediano, junto a sus asociaciones contextuales podrían estar vinculados posiblemente a ocupaciones de corta duración y con un número limitado de personas, en tanto que los fogones de gran tamaño asociados a restos de cetáceos o a abundantes restos de guanaco podrían corresponder a ocupaciones de más larga permanencia en el lugar, o bien a una gran concentración de población, o a ambos factores combinados (Massone, 2017).

Por otra parte, los estudios antracológicos 
realizados han proporcionado información de especial interés sobre la leña utilizada para la combustión, en los sitios septentrionales de la isla, tanto en el interior como en la costa.

En los sitios Tres Arroyos 1 y Tres Arroyos 4 , el estudio de los carbones recuperados de los fogones $N^{\circ} 1,8$ y 11 , respectivamente, indica que la principal fuente de combustible utilizado provino de especies arbustivas, predominantemente romerillo. En los fogones $\mathrm{N}^{\circ} 12$ y 13 de la impronta $88 \mathrm{del}$ campamento Tres Arroyos 14, se utilizó romerillo en forma exclusiva. Por otra parte, en el fogón 1 de la cueva Tres Arroyos 1, y en el fogón 11 del alero Tres Arroyos 4, Berberis sp., representa el segundo grado de dominancia con respecto a la leña utilizada en la combustión. Solo en el fogón 11 se encontró escasa presencia de un género arbóreo, Nothofagus sp., que podría corresponder a lenga o ñirre. Esta información se ve complementada con aquella proporcionada por un fragmento identificado entre los carbones dispersos del mismo alero (muestra 3), que corresponde a Nothofagus betuloides, coihue. Los cinco fogones referidos son fogones de tamaño mediano, localizados en sitios ubicados a unos $20 \mathrm{~km}$ al interior de la costa atlántica, en la localidad de Tres Arroyos.

En la localidad, la vegetación arbustiva más frecuente en la actualidad es el romerillo, acompañada con menor representación por Berberis sp. (Dollenz, 1991). Esto significa que los selk'nam que ocuparon los sitios Tres Arroyos 1 (niveles superiores), Tres Arroyos 4 y Tres Arroyos 14 (88), utilizaron de preferencia el combustible que estaba a disposición a escala local. El bosque de Nothofagus más cercano a Tres Arroyos se encuentra en el sector de Río Chico, ubicado a unos $25 \mathrm{~km}$ hacia el sur.

Los carbones de romerillo del sitio Tres Arroyos 14, impronta 88, pertenecen a ramas pequeñas con un diámetro no superior a $0,7 \mathrm{~cm}$. Cuatro de esos fragmentos presentan grietas en la anatomía, lo que podría deberse a combustión de ramas verdes. Por otra parte, el análisis de los anillos de crecimiento en las muestras de romerillo, en los casos que fue posible contarlos, indica que se trata de individuos longevos, en relación a los diámetros mínimos que presentan (> a 12 anillos). Es probable que fueran individuos sometidos a un fuerte stress, lo que les habría impedido desarrollar un leño de mayor grosor.

En el sitio costero Marazzi 38, si bien predominan las especies arbustivas utilizadas en la combustión del fogón (59,4\% de los carbones), es también importante el uso de madera de árboles (36,5\% de los carbones). En el sitio Marazzi 32 la proporción de carbones que proceden de madera de árboles es aún mayor alcanzando un 45,5\% del total de carbones, versus $44,3 \%$ de carbones vinculados a vegetación arbustiva (Solari 2005).

Ambos sitios se encuentran en el fondo de la bahía Inútil en un ambiente de estepa, sin presencia de árboles. No obstante, es muy frecuente encontrar abundante cantidad de grandes troncos varados en su extensa playa. Al respecto, el teniente de la armada chilena, Ramón Serrano Montaner, quién acampó en ese sector en 1879, describe ...no hay un solo arbusto que pueda servir para el fuego, y nos vimos obligados a acarrear leña de la que arroja el mar a la playa para nuestra cocina (Serrano Montaner en Martinic, 2002, p. 199). De lo anterior se desprende que en tiempos de los selk'nam ya había leña de árboles varados en la playa, disponibles para ser usados en la combustión de los fogones. Por tanto, habrían contado con una reserva de madera seca y de buena calidad. Por las características del fondo de bahía Inútil y la circulación de las corrientes marinas de la bahía, es posible que esta situación de playas receptoras de troncos de árboles flotados y transportados por el mar se haya dado incluso en tiempos de los antecesores de los selk'nam. Resulta improbable que la presencia de carbones de especies arbóreas en los sitios Marazzi 32 y 38 se deba a un acarreo de leña desde los bosques de lenga de la sierra Carmen Sylva. En ese caso, la distancia mínima de traslado de madera habría sido algo superior a $12 \mathrm{~km}$, esfuerzo innecesario si se disponía de leña en la playa.

Tanto en Marazzi 32 como en Marazzi 38 hay fogones de gran tamaño asociados a restos de cetáceos, con huellas por modificaciones artificiales (Fogones $\mathrm{N}^{\circ} 16,17$ y 20). Estas grandes áreas de quema, inusuales para otros sitios selk'nam o de sus antecesores, estudiados en el norte de Tierra del Fuego, hacen pensar que, para mantener un amplio fuego sostenido en el tiempo, debieron necesitar abundante combustible, lo que pudo ser proporcionado en gran medida por los troncos 
varados en la playa.

A partir de todas las muestras de carbón analizadas, tanto de sitios costeros como del interior, se puede concluir que la estrategia de los selk'nam del norte y de sus posibles antecesores, en cuanto al uso de la madera para combustión de los fogones, consistió en aprovechar los recursos locales de la estepa. En los sitios interiores de la localidad de Tres Arroyos se utilizó de preferencia el romerillo y los Berberis. De modo diferenciado, en los sitios del fondo de bahía Inútil, el uso de madera de árboles alcanzó una especial significación, junto a las especies arbustivas locales.

El predominio o significativo uso de madera de especies arbóreas, en las muestras de los sitios Marazzi 32 y Marazzi 38, podría tener su explicación en la necesidad de sostener por tiempo prolongado el fuego, en forma abundante en amplias áreas de combustión, lo cual suma un argumento en apoyo de procesos de agregación de población en la localidad, para un evento de larga duración, vinculado con el consumo y/o utilización de restos de un gran cetáceo.

\section{AGRADECIMIENTOS}

Manifestamos nuestra gratitud a las instituciones DIBAM, UMAG, UACh y UNICEN (Olavarría), por apoyar de diferentes formas el presente estudio. Expresamos también nuestro agradecimiento a los proyectos de investigación FONDECYT 90-0001, 1960027, 1020004, 7020004, 1060020 y 1140939, que permitieron obtener la información necesaria, en distintos períodos de tiempo. Agradecemos al Archivo Fotográfico-Histórico: Centro de Estudios del Hombre Austral, Instituto de la Patagonia, UMAG, por permitir el uso de la fotografía de un fogón Selk'nam. Agradecemos, de modo especial, las variadas sugerencias y comentarios de los arqueólogos Gustavo Politis, Rafael Curtoni, Luis Borrero, Mónica Salemme, César Méndez, Flavia Morello, Donald Jackson y Alfredo Prieto, a distintos aspectos relacionados con el estudio arqueológico de los fogones del Norte de Tierra del Fuego. A Pedro Cárdenas por su constante apoyo en terreno, a todos los colegas que participaron en los distintos trabajos arqueológicos referidos a los fogones; a César Méndez y Víctor Méndez por calibrar las dataciones presentadas; a la colega Roxana Torres por la elaboración de los mapas de ubicación de los sitios y planta de Marazzi 32, a partir de la planta inicial preparada por Flavia Morello y a la tesista doctorante en arqueología Alia G. Pichincura, por la preparación de los gráficos. A las personas de Tierra del Fuego que de manera silenciosa nos prestaron su ayuda y hospitalidad durante los trabajos de terreno: don René Milicevic y Familia, don René Lillo y Familia, don Alfonso Fernández y Familia, a los señores Bernardo Krusell, Ivo Robertson, Carlos Descourvieres, José Soto, Iris Sánchez, Marcos Martic, José Calbuante, Blanca Curguán y Pedro Mansilla.

\section{BIBLIOGRAFÍA}

Bahamondes, M. (2004). Las aves en la cultura selk'nam: estudio del registro arqueofaunístico de cuatro sitios de bahía Inútil (Tierra del Fuego). Magallania, 32, 163189.

Bailey, G. (2007). Time perspectives, palimpsests and the archaeology of time. Journal of Anthropological Archaeology, 26, 198-223.

Beauvoir, J.M. (1915). Los selk'nam indígenas de la Tierra del Fuego. Buenos Aires: Talleres gráficos de la Compañía General de Fósforos.

Borella, F. (2003). Informe en relación a las concentraciones de restos de cetáceo en el sitio Marazzi 32, bahía Inútil. Tierra del Fuego. En M. Massone, F. Morello, J. Gibbons \& L. Borrero. Las ballenas en el mundo Selk'nam: un enfoque desde la arqueología y otras disciplinas en el norte de Tierra del Fuego. Informe de avance primer año. Proyecto Fondecyt $N^{\circ} 1020004$.

Borrero, L. A. (2003). Taphonomy of the Tres Arroyos 1 Rockshelter, Tierra del Fuego, Chile, Quaternary International, 109-110, 87-93.

Borrero, L. A., Borella, F., Massone, M., \& Morello, F. (2009). Relevancia arqueológica de los varamientos de cetáceos en el estrecho de Magallanes (Tierra del Fuego-Chile). En Temas de Arqueología 2: Estudios tafonómicos y zooarqueológicos. Acosta, Loponte \& Mucciolo (Comp), 1-13.

Bridges, L. (2000) [1949]. El último confín de la Tierra. Buenos Aires: Editorial Sudamericana.

Caruso, L. (2014). Los usos de la madera entre los cazadoresrecolectores selk'nam. En J. Oría y A. M. Tivoli (Eds.), Cazadores de mar y tierra. Estudios recientes en arqueología fueguina (pp. 335-356), Buenos Aires. 
Chapman, A. (1986). Los selk'nam, la vida de los onas. Buenos Aires: Emecé Editores.

Coiazzi, A. (1997) [1914]. Los indios del archipiélago fueguino. Punta Arenas: Editorial Ateli.

De Agostini, A. (2005) [1956]. Treinta años en Tierra del Fuego. Buenos Aires: Ediciones Elefante Blanco.

Dollenz, O. (1991). La vegetación del cerro de Los Onas. En M. Massone, D. Jackson \& A. Prieto. Perspectiva arqueológica del sistema adaptativo selk'nam en la zona norte de Tierra del Fuego. Informe anexo primer año. Proyecto Fondecyt 90-0001.

Gallardo, C. (1910). Tierra del Fuego; Los Onas. Buenos Aires: Cabaut y Cia.

Gusinde, M. (1982) [1931]. Los indios de la Tierra del Fuego. Vol. I Los selk'nam. Buenos Aires: Centro Argentino de Etnología.

Laming-Emperaire, A. (1965-68). Le site de Marazzi en Terre de Feu. Cuaderno de terreno $N^{\circ} 19$. Ver diario de diciembre de 1967, pag. 31. Depositado en el Centro de Estudios del Hombre Austral, del Instituto de la Patagonia, Universidad de Magallanes, Punta Arenas.

Laming-Emperaire, A. (1968). Le site Marassi en Terre de Feu. Rehue, 1, 133-143.

Laming-Emperaire, A., D. Lavalle y R. Humbert. (1972). Le site de Marazzi en Terre de Feu. Objets et Mondes. Tomo XII, 2, 225-244.

Lothrop, S. (1928). The Indians of Tierra del Fuego. Museum of American Indian. New York.

Mansur, M. E., Maximiano, A., Piqué, R., \& Vicente, O. (2007). Arqueología de rituales en sociedades cazadoras recolectoras. Una aproximación desde el análisis del espacio socialmente producido. En F. Morello, M. Martinic, A. Prieto y G. Bahamonde (Eds.), Arqueología de fuego-Patagonia. Levantando piedras, desenterrando huesos... y develando arcanos (pp. 741-754). Punta Arenas: Ediciones CEQUA.

Markgraf, V. (1991). Late pleistocene environmental and climatic evolution in southern South America. Mamberger Geogr. Schr. 11, 271-281.

Markgraf, V. (1993). Paleoenvironments and paleoclimates in Tierra del Fuego and southernmost Patagonia, South America. Palaeo, 102(1-2), 53-68.

Martin, F. (2006). Carnívoros y huesos humanos de FuegoPatagonia. Aportes desde la tafonomía forense. Colección Tesis de Licenciatura. Buenos Aires: Sociedad Argentina de Antropología.

Martinic, M. (2002). Marinos de a caballo. Valparaíso: Editorial Puntángeles.

Massone, M. (2004). Los cazadores después del hielo.
Colección de Antropología VII. Santiago: Centro de Investigaciones Diego Barros Arana.

Massone, M. (2010). Abrigos rocosos de Magallanes en la transición Pleistoceno-Holoceno. Actas XVII Congreso Nacional de Arqueología Chilena Valdivia 2006. Tomo 2, 729-740, Valdivia.

Massone, M. (2017). Fuego, fogones y contextos arqueológicos de los cazadores recolectores tardíos en el norte de Tierra del Fuego. Tesis para optar al Grado de Doctor en Arqueología, Facultad de Ciencias Sociales, Universidad Nacional del Centro de la Provincia de Buenos Aires, Olavarría.

Massone, M., Jackson, D., \& Prieto, A. (1993). Perspectiva arqueológica de los selk'nam. Colección de Antropología I. Santiago: Centro de Investigaciones Diego Barros Arana, DIBAM.

Massone, M., \& Morello, F. (2007). Los cetáceos en el mundo selk'nam: una evaluación arqueológica. En F. Morello, M. Martinic, A. Prieto \& G. Bahamonde (Eds.), Arqueología de Fuego-Patagonia. Levantando piedras, desenterrando huesos... y develando arcanos (pp. 709-721). Punta Arenas: Ediciones CEQUA.

Moore, D. M. (1983). Flora of Tierra del Fuego. A. Nelson, England, Missouri Botanical Garden USA.

Morello, F., Sánchez, R., \& San Román, M. (1997). Sondeos estratigráficos y excavación en Tres Arroyos. Sitios Ta4, Ta-18 y Ta-10. En Massone et al. Hombre temprano y paleoambiente en Tierra del Fuego. Informe de Avance 1er año. Proyecto Fondecyt $N^{\circ} 1960027$.

Morello, F., Contreras, L., \& San Román, M. (1999). La localidad de Marazzi y el sitio arqueológico Marazzi I, una re-evaluación. Anales del Instituto de la Patagonia, Serie Ciencias Sociales, 27, 183-197.

Muñoz, A. S. (2000). El procesamiento de guanacos en Tres Arroyos 1, Isla Grande de Tierra del Fuego. En Desde el país de los gigantes. Perspectivas arqueológicas en Patagonia (pp. 499-517). Río Gallegos: Universidad de la Patagonia Austral.

Ozán, I. L., \& Borrero, L. A. (2017). Sobre el origen de las depresiones circulares del talud de Tres Arroyos, Tierra del Fuego. Ms.

Pisano, E. (1977). Fitogeografía de Fuego-Patagonia chilena I. Comunidades vegetales entre las latitudes $52^{\circ}$ y $56^{\circ} \mathrm{S}$. Anales del Instituto de la Patagonia, 8, 121-250.

Rancussi, M., Nishida, M., \& Nishida, H. (1987). Xylotomy of important chilean woods. In Nishida M. (ed) Contributions to the botany in the Andes II. Ed. Academia Scientific Book, Tokio, 68-158.

Rojas, G. (1998). Vegetación, potencialidad alimentaria y 
utilitaria, para el indígena de Tres Arroyos, Tierra del Fuego, Chile. Anales del Instituto de la Patagonia. Serie Ciencias Naturales, 26, 91-99.

Rojas, G. (1999). Vegetación Holocénica de Tres Arroyos y Marazzi, Tierra del Fuego. En M. Massone, A. Prieto, D. Jackson, X. Prieto, G. Rojas, R. Seguel \& L. A. Borrero. Hombre temprano y paleoambiente en Tierra del Fuego. Proyecto Fondecyt $N^{\circ} 1960027$, informe final tercer año.

Segers, P. (1891). Hábitos y costumbres de los indios aonas. Boletín del Instituto Geográfico Argentino, XII, 5682.

Solari, M. E. (1993). L'Homme et le bois en Patagonie et Terre de Feu au cours des six derniers millénaires: recherches anthracologiques au Chili et en Argentine. Tesis doctoral. Universidad de Montpellier, Francia.
Solari, M. E. (2005). Análisis antracológico de los sitios Marazzi 32, Marazzi 38 y Punta Catalina 3 (Tierra del Fuego, Chile). En Massone et al. Las Ballenas en el mudo Selk'nam: un enfoque desde la arqueología y otras disciplinas, en el norte de Tierra del Fuego. Informe Final, tercer año, Proyecto Fondecyt 1020004.

Torres, J. (2007). El rol de los recursos ictiológicos y las prácticas de pesca, en las ocupaciones litorales de los grupos selk'nam y pre selk'nam del norte de Tierra del Fuego. Memoria para optar al título profesional de arqueóloga. Departamento de Antropología, Facultad de Ciencias Sociales, Universidad de Chile, Santiago.

Wagemann, W. (1949) Maderas chilenas: contribución a su anatomía e identificación. De Lilloa, tomo XVI, 304350 . 
